\title{
Fiber Reinforced Cement Mortars Degradation after their Exposure to Fire Conditions
}

\author{
N.D. Nikoloutsopoulos, A.B. Sotiropoulou and Z.G. Pandermarakis ${ }^{\text {a }}$ \\ Department of Civil and Structural Engineering Technology Teachers \\ School of Pedagogical and Technological Education (ASPETE) \\ Irene Train Station - Athens - Greece
}

\begin{abstract}
Cement based mortars reinforced by glass and polypropylene fibres were exposed to fire conditions up to $900{ }^{\circ} \mathrm{C}$ from $10 \mathrm{~min}$ to 2 hours and after their slow cooling, were tested under compression and bending loadings. We can see that three distinct stages are appeared. At first, up to $300^{\circ} \mathrm{C}$, a not absolutely specified behaviour is appeared. Reinforced mortar's mechanical response is depended on temperature level, time duration and type of cement composite. So, its strength can be slightly increased, remains unaltered or can be even reduced. At the following stage from $300^{\circ} \mathrm{C}$ up to $800^{\circ} \mathrm{C}$, a gradual general degradation is appeared. Mortar's strength and rigidity are rapidly reduced so low, reaching approximately the $10 \%$ of their initial values. At the same time yielding strain is increased, leading to an almost constant toughness. The whole degradation of cement composite is completed at the third stage where a total destruction is appeared. At the temperature level of $900^{\circ} \mathrm{C}$ and above the aggregates decomposition is recorded, giving an grained like material.
\end{abstract}

\section{Introduction}

After some very serious catastrophic events, as the fire at Mont Blanc tunnel in France and the collapse of WTC twin towers in New York, there is a great interesting about the destructed action of fire on building materials and structures. The fire growth near or in a structure domain could lead to the development of very high temperatures, exposing its elements to strong thermal loadings and structural modifications. Also, phase transformations, decompositions and the diminishing of their mechanical properties, weak largely the whole structure. At the same time a quick fire expansion and the demand for quick extinguishing, usually by water, leads to thermal shocks with a more harmful occurrence [1].

The concrete structures in the case of fire appear many positive features against to others for many reasons. Their low thermal conductivity, their chemical decomposition at high temperature and the common practice of masonry layers on free concrete surfaces are some of their benefits in contrast to aluminum, wood or even steel structures [2]. Using protecting masonry layers helps not only for a

a e-mail: z.g.panderma@gmail.com

This is an Open Access article distributed under the terms of the Creative Commons Attribution-Noncommercial License 3.0, which permits unrestricted use, distribution, and reproduction in any noncommercial medium, provided the original work is properly cited. 
not direct exposure of loading structure to fire and so to high temperature, but also act as a barrier to chemicals and carbon fog volatilities. At the same time, masonries reduce the appearing thermal shock during the stage of fire grow and it's extinguish too.

The rather brittle response of cement based mortars could be reduced by adding short random distributed flexible fibers in them. Usually, glass and propylene fibers are added in order to achieve a more toughened behavior. The main mechanism for this is the ability of enhanced carrying loads by the tips of the appearing cracks. Also strength of mortars can be affected by their composition, the fiber and, the interface features and of course the manufacture conditions.

\section{Specimens preparation and exposure to high temperatures}

By this study we try to investigate the response of fibre reinforced mortars to fire conditions. Also, we want to see if we can use marble by-products as aggregate in mortar composition [3]. So, all aggregates in this study were marble with sizes up to $4 \mathrm{~mm}$.

\subsection{Materials and specimens preparation}

High strength cement of I52.5 type was used. Marble aggregates up to $4 \mathrm{~mm}$ size were added with cement to aggregate proportion be at $1 / 3$. The attained water to cement ratio was 0.51 and the volume percentage of the added short random distributed short fibres was $0,26 \%$ for the glass (GL) reinforced specimens and the same for the polypropylene (PP). Specimens were prepared in suitable standard mortars moulds with dimensions of $16 \mathrm{cmx} 4 \mathrm{~cm} \times 4 \mathrm{~cm}$ (fig.1). After their compaction in moulds they left for 28 days in a water tank and then at room conditions for another 28 days in order to equilibrate.
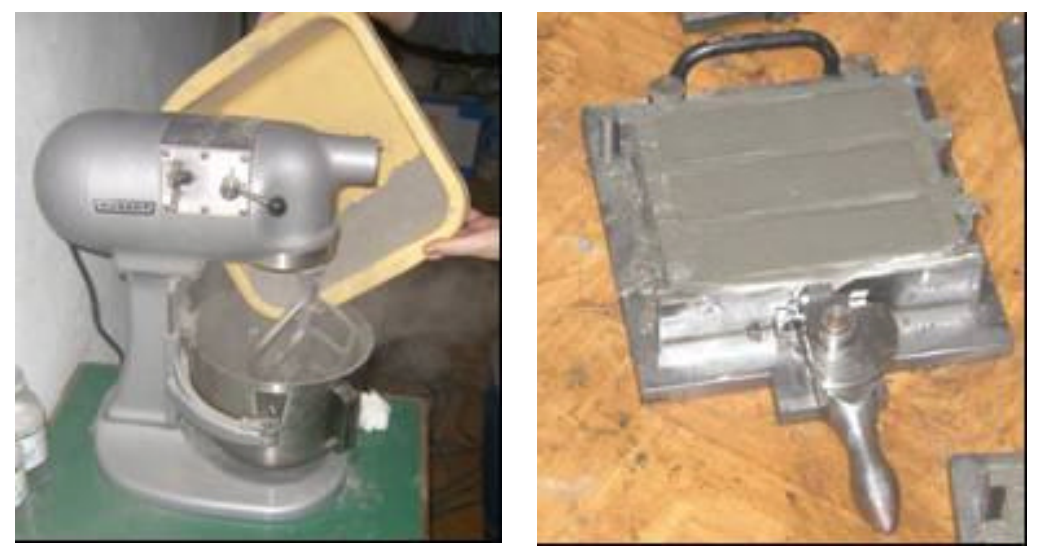

Fig. 1a,b. Mixer and standard mortar moulds.

\subsection{Temperature exposure}

The specimens after their hardening period, placed in a high temperature oven (fig.2) and they left to a wide range of temperatures for 10,30, 60 and 120min. During the heating period the heating 
rate was kept at $30^{\circ} \mathrm{C} / \mathrm{min}$ for low temperatures up to $400^{\circ} \mathrm{C}$ and at $2^{\circ} \mathrm{C} / \mathrm{min}$ for higher temperature levels. During cooling period the rate was kept at $20^{\circ} \mathrm{C} / \mathrm{min}$.

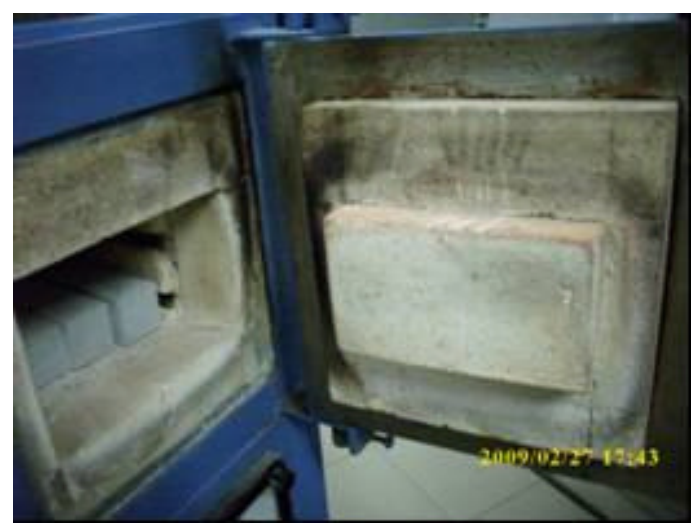

Fig. 2. The high temperature oven.

\subsection{Mechanical response and conclusions}

After a day rest, specimens were tested by three point bending (fig.3 and 4). The load was measured by load cell, whereas strain was measured by suitable attached strain gauges at the bottom tensile specimen layer. High temperature exposed specimens were tested also to compression test, and were examined by ultrasonic heads and for density changes.

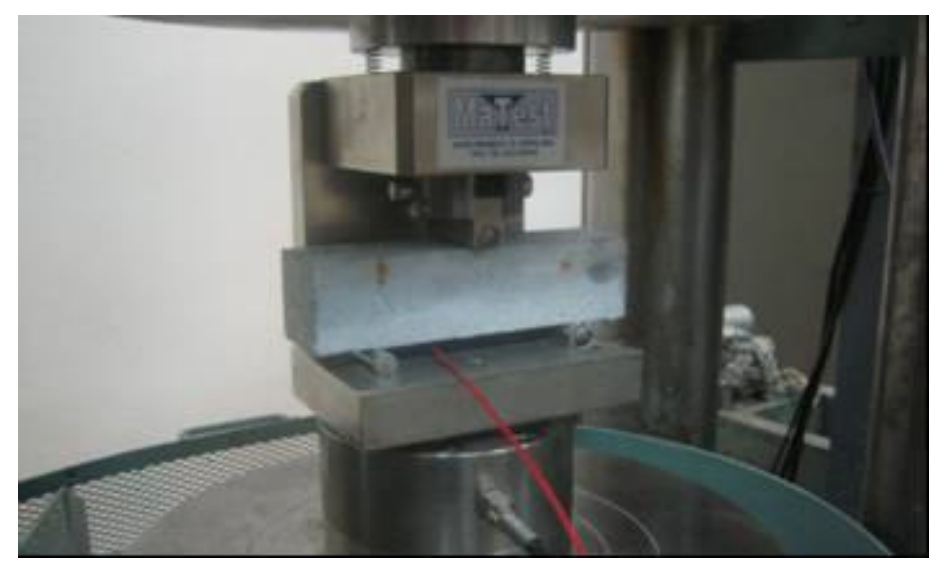

Fig. 3. Bending test arrangement.

. Bending strength was estimated by the known bending rule, suitably modified for our case of standard mortar specimens and apparatus: 


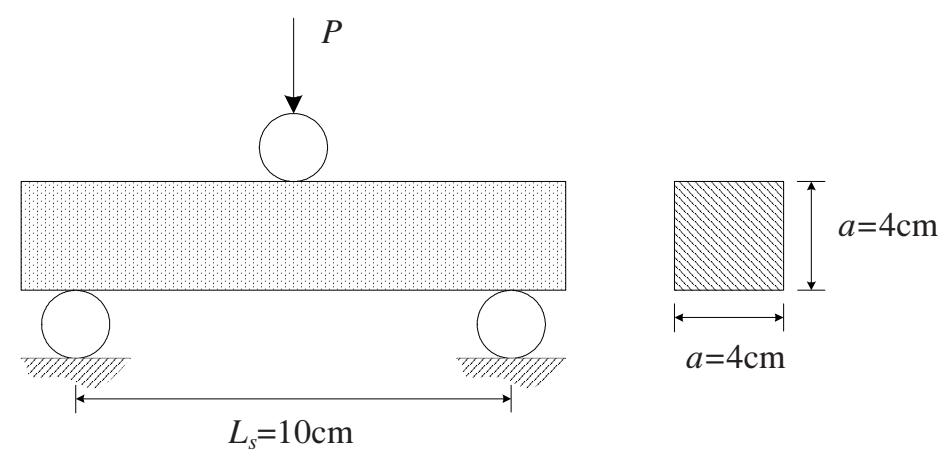

Fig. 4. The characteristic lengths of standard bending apparatus of mortars.

$$
\sigma_{b}=\frac{15 P_{\max } L_{s}}{a^{3}}
$$

where bending strength $\sigma_{b}$ is giving in (MPa), the load $P_{\max }$ is giving in $(\mathrm{kN})$ and the support length $L_{\mathrm{s}}$ and side $a$ of the square section of specimen in $(\mathrm{cm})$.

At fig. 5 and 6 we show the changes of bending strength of polypropylene fibre reinforced cement based mortar and of glass fibre respectively

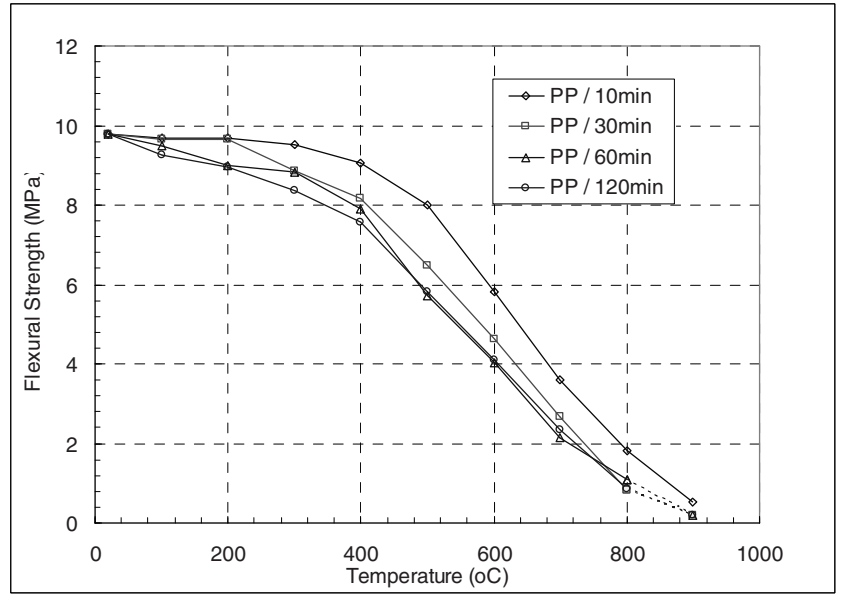

Fig. 5. Flexural strength via temperature and time exposure for PP fibre reinforced mortar.

Exactly, similar results were obtained for compression strength, flexural and compression modulus, densities and ultrasonic velocities. From these, we can see that due to the fire exposure, three distinct stages are appeared. At the first (that can be specified by temperatures up to $300^{\circ} \mathrm{C}$ ), the mechanical response of cement composites appear small variations that depend basically on the loss of physical bounded water and the curing acceleration. In each case at the end of this stage a strength loss of about $10 \%$ of initial fiber reinforced mortar is appeared. At the next stage from $300^{\circ} \mathrm{C}$ up to $800^{\circ} \mathrm{C} \mathrm{a}$ progressive diminishing of strength is happened due to the dehydrations of calcium hydroxide. The decomposition of $\mathrm{Ca}(\mathrm{OH})_{2}$ that accelerates at the range of 400 to $500^{\circ} \mathrm{C}$ leads gradually to serious 
damage of cement based mortars. In this region a color differentiation is appeared giving a rather gray-green color for burned specimens [4].

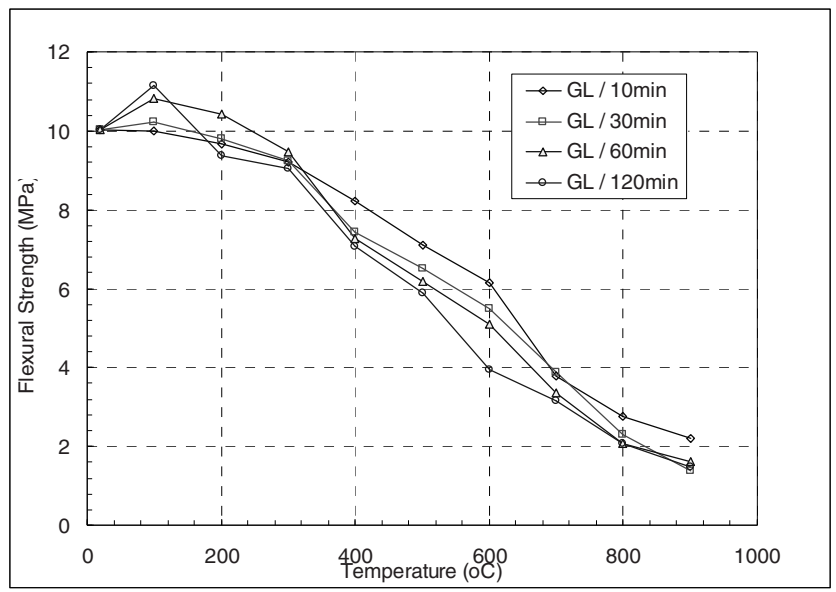

Fig. 6. Flexural strength via temperature and time exposure for glass (GL) fibre reinforced mortar.

Finaly, at the third stage a general destruction of mortar is appeared due to the decomposition of calcium carbonate, the main constituent of marble aggregates. We can see that the duration of time exposure leads to a higher degradation of mortar but with a lower rate. As we can see from fig.7a and $b$, the glass fiber reinforced mortars appear a systematically higher strength than that of polypropylene fiber reinforced mortars mainly due to the stiffer response of glass fibers.
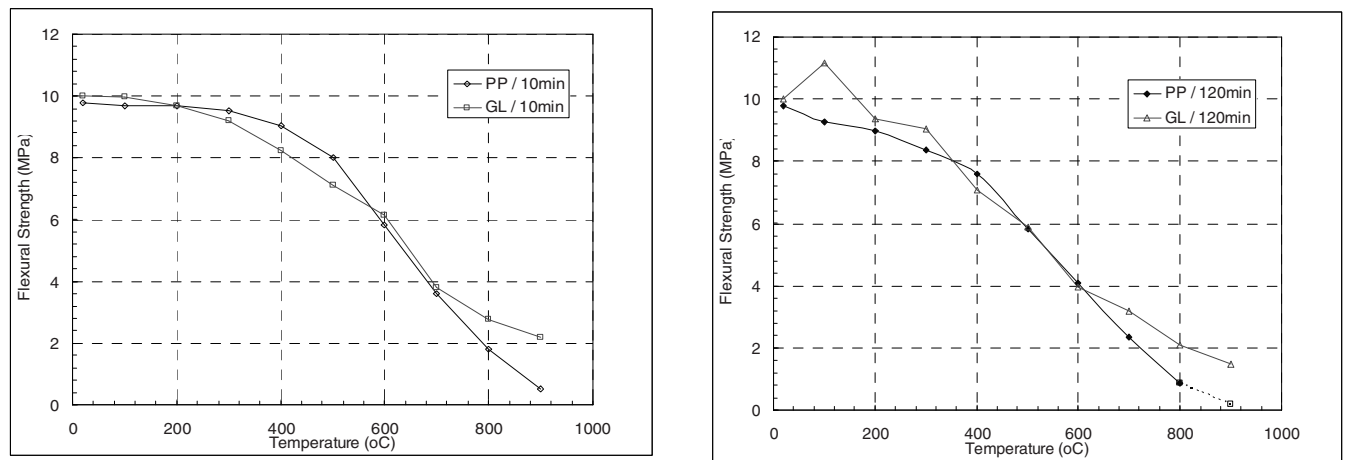

Fig. 7a,b. The relative strength variation of PP and GL fibre reinforced mortars for 10 and 120 min time duration of high temperature exposure.

At the range of 300 to $500^{\circ} \mathrm{C}$ a reversion of their strength is appeared. This can be attributed to the fact that at the temperature level of $160^{\circ} \mathrm{C}$ the PP fibers are melted, whereas at the temperature of $590^{\circ} \mathrm{C}$ are burned and this can be the reason for the enhanced strength of PP mortars in the above narrow region. At the temperature level of about $800^{\circ} \mathrm{C}$ the glass fibers are melted resulting to a higher consistency of the degraded cement matrix.

In all cases high thermal stresses due to different thermal coefficients and thermal gradient are appeared. These thermal stresses lead to an enhanced crack formation in specimens and so to a lesser 

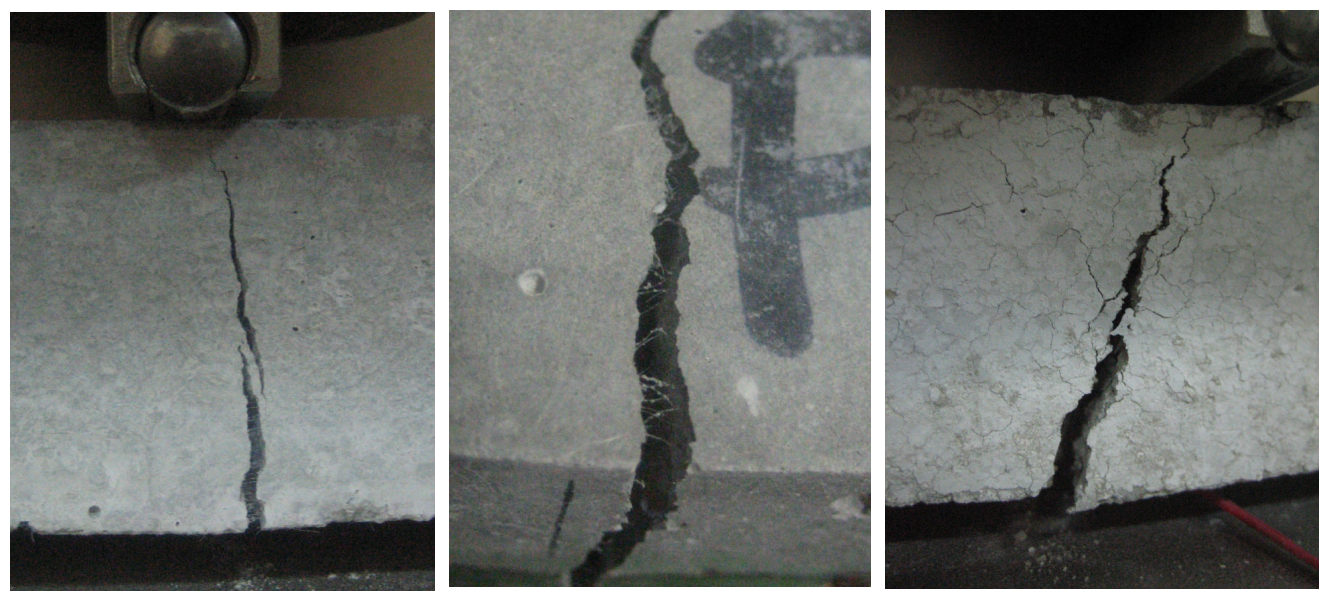

Fig. 8a,b,c. Specimens cracking during bending loading.

strength (fig.8). At left of fig.8, a PP fibre reinforced mortar specimen burned at $300^{\circ} \mathrm{C}$ for $10 \mathrm{~min}$, whereas at right the same mortar composite specimen burned at $900^{\circ} \mathrm{C}$ for the same time. At the middle figure we can see the pull-out effect of PP fibres during tensile fracture of bending specimens.

At the temperature of $400^{\circ} \mathrm{C}$ an about $40 \%$ reduction of mortar mechanical strength is appeared, reaching to $10 \%$ of its initial strength as temperature approximate the $900^{\circ} \mathrm{C}$. Measurements of elasticity modulus gave also a dramatic falling from about $32 \mathrm{GPa}$ to about $1 \mathrm{GPa}$ for 2 hour exposure at $900^{\circ} \mathrm{C}$ for both the fiber reinforced mortars. At the same time, ultrasonic inspections presented variations proportional to these of strength, with $4360 \mathrm{~m} / \mathrm{s}$ calculating sound velocity for unburned specimens to approximately $1270 \mathrm{~m} / \mathrm{s}$ and 1380 for burned PP fiber reinforced and GL reinforced mortars at $900^{\circ} \mathrm{C}$ for two hours.

We can say that, as the temperature of exposure is increased the mechanical strength, the rigidity and of course the density of a burned mortar is decreased, whereas, the appeared strains, the microcracking, the deflections, the energy damping and generally the non-linear responses are increased by a similar way.

\section{References}

1. M. Abramowicz, R. Kowalski, J. Civil Eng. Manag., XI(2), 85 (2005)

2. A.G. Gupta Fire in Buildings, Chapter 25-SES02, (Indian Instituted of Technology, Kharagpur, 2006)

3. A.B. Sotiropoulou, Z.G. Pandermarakis, 16th European Conference of Fracture, 539 (Alexandroupoli Greece, July 3-7, 2006)

4. J.P. Ingham, 11th Euroseminar on Microscopy Applied to Building Materials, (Porto Portugal. June 5-9, 2007) 